\title{
A CORTINA SE ABRE: OS OBSTÁCULOS EDUCACIONAIS DADO ÀS CRIANÇAS CIRCENSES SOB A ÓTICA DAS FAMÍLIAS
}

\author{
THE CURTAIN OPENS: FAMILIES' PERSPECTING ON THE \\ EDUCATIONAL OBSTACLES POSED ON CIRCUS CHILDREN
}

\author{
Lidiane Evangelista Lira ${ }^{1}$ \\ Cintia Daniele Silva Neves ${ }^{2}$
}

\section{RESUMO}

Esta pesquisa aborda questões relacionadas aos desafios da educação escolar às demandas da criança/jovem circense, dada as suas especificidades ao longo do processo de escolarização. Identificaremos tais demandas, no tocante ao acesso e permanência, com qualidade social, à educação escolar, apontando seus limites e possibilidades. Nossa abordagem metodológica articula-se à pesquisa descritiva e exploratória mediante à aplicação de entrevista semiestruturada, com dois pais de crianças e adolescentes circenses em idade escolar, mediante um roteiro prévio e um questionário desenvolvido com a representante de ensino de Garanhuns/PE. As entrevistas semiestruturadas, gravadas e transcritas, decorreram nos municípios de Garanhuns/PE e Saloá/PE, em 2018. Observamos diversas dificuldades relacionadas ao acesso da criança circense à escola, que vem da efetivação da matrícula às práticas efetivas pedagógicas. Os resultados indicam falta de cumprimento das políticas públicas específicas, bem como falta de cumprimento das leis existentes para garantir o direito a uma educação de qualidade.

Palavras-chave: Educação; Circo; Children; Políticas públicas.

\begin{abstract}
This research addresses issues related to the educational challenges faced by circus children and teenagers in light of their specificities throughout the schooling process. We identified their demands on access and permanence, social quality, school education, pointing out its limits and possibilities. Our methodological approach is linked to descriptive and exploratory research by applying semistructured interviews with two parents of school-age children and teenagers, using a script and a questionnaire developed with the teaching representative of Garanhuns / PE. Semi-structured interviews, recorded and transcribed, took place in Garanhuns / PE and Saloá / PE, in 2018. We observed several difficulties related to circus children's access to the school, from effective enrollment to effective pedagogical practices. The results indicate a lack of compliance with specific public policies and a lack of compliance with existing laws to guarantee the right to quality education.
\end{abstract}

Keywords: Education; Circus; Children; Public policies.

\footnotetext{
${ }^{1}$ Atualmente é Professora adjunta da Universidade de Pernambuco - UPE Campus Garanhuns - PE. Doutora em Educação pela Universidade Federal de Alagoas - UFAL. e-mail: lidiane.lira@upe.br

${ }^{2}$ Licenciada em Pedagogia pela Universidade de Pernambuco - UPE. e-mail: cintiadaniele2007@ hotmail.com
} 


\section{INTRODUÇÃO}

É sabido que a educação perpassa por diferentes setores institucionais, seja no contexto familiar ou social, estamos constantemente aprendendo. Ainda que de natureza inevitável (BRANDÃO; 2007), o acesso à educação, especificamente a educação formal, essa institucional e obrigatória tem a função de "prover aos indivíduos os conhecimentos e experiências culturais que os tornam aptos no meio social e transformá-lo em função de necessidades econômicas, sociais e políticas da coletividade" (LIBÂNEO, 1994, p. 17). Nesse seguimento, é urgente auxiliar os estudantes a tomarem consciência de seu papel perante a sociedade e na construção do seu "eu", através dos novos conhecimentos adquiridos. Todavia, a educação atravessa alguns percalços dado que a atuação efetiva da criança na escola decorre em função dos projetos de sociedade e de como os processos educativos foram construídos, isto é de relações que repercutem em inclusões ou exclusões sociais. Em nosso estudo, nos referimos às demandas da criança circense ao longo de seu processo de escolarização. Essas crianças vivem em situação de itinerância e precisam de atendimento diferenciado, devido as constantes mudanças de cidades e, consequentemente, de escolas.

As crianças que vivem em situação de itinerância são conhecidas por estarem fora do sistema de ensino regular. Dentre esse grupo estão os filhos de artistas, jogadores de futebol, grupos nômades como os filhos de ciganos, bem como as crianças artistas circenses que acompanham os seus pais nas atividades de trabalho. Buscamos conhecer a realidade de crianças circenses, a fim de compreender como se processa a educação dessas crianças, bem como apresentar, a partir de uma pesquisa exploratória, as dificuldades relacionadas ao acesso dessas crianças à educação formal sob a ótica das famílias.

Cientes da garantia de ensino obrigatório e dos direitos consagrados à criança (BRASIL, 1988; 1990), medidas efetivas de acompanhamento desse direito, no âmbito das escolas, na figura do professor devem resultar no reconhecimento que uma educação de qualidade se faz, a partir do momento que compreendemos os complexos processos de produção dentro dos quais as crianças vivem. Em outras palavras, o conhecimento sobre quem é o aluno e suas vivências são fundamentais para um trabalho de acompanhamento 
efetivo (ZABALA, 1998). Destarte, ao colocarmos em evidência a singularidade $^{3}$ da criança/juventude circense, destacamos suas demandas e a forma de acompanhamento humanizado e diligente necessário por parte do sistema educativo.

Dessa maneira, o trabalho é composto por uma pesquisa descritiva e exploratória com procedimentos instrumentais de campo e levanta a seguinte questão: Quais as práticas pedagógicas no trato às demandas da criança circense, sob a ótica das famílias, ao longo do processo de escolarização? Para tanto, é necessário debruçarmos sobre o contexto histórico que envolve a origem de atenção dada à criança (ARIÈS, 1986), articulando as orientações legais à discussão de uma prática educativa efetiva (LUCKESI, 2011; SILVA; ABREU, 2009). A partir dessa pesquisa buscaremos compreender as demandas educativas da juventude circense em seu acesso à educação formal, identificando as demandas específicas da criança/jovem circense relativas ao seu acesso e à sua permanência com qualidade social, no espaço escolar, bem como, investigar os limites e possibilidades pedagógicas no trato às demandas educativas da criança/jovem circense na escola.

\section{RESPEITÁVEL PÚBLICO: O CIRCO CHEGOU!}

O espetáculo circense é histórico, por ser uma das manifestações artísticas mais antigas, sua origem é imprecisa, dos chineses aos gregos, dos egípcios aos indianos, quase todas as civilizações antigas praticavam algum tipo de arte circense (JUNIOR; SILVA; LAZIER et al., 2013). O estudo de Castro (1997) evidenciou que na China as artes circenses foram descobertas em pinturas de quase 5.000 mil anos. Dentre as artes circenses mais antigas, estão: acrobacias, contorcionismos e equilibrismos, os guerreiros chineses usavam as acrobacias como forma de treinamento militar.

Silva e Abreu (2009, p. 25), relatam que: “desde o final do século XVIII, na Europa Ocidental, grupos e formas de expressões artísticas diversas foram se constituindo e se identificando como circenses". E esses grupos se espalharam por toda Europa e demais

\footnotetext{
${ }^{3}$ A singularidade da criança circense ou ainda de um jovem cuja vivência é itinerante e plural reverbera no fato desses sujeitos possuírem interesses plurais, dada pela constituição da cultura artística que o circunda e, nesse sentido, demandar um direcionamento pedagógico que garanta a sua permanência na escola, é voltar a atenção para o que é particular para o desenvolvimento desses sujeitos.
} 
países, mantendo características originárias da época, bem como foram se transformando de acordo com a sociedade na qual estavam inseridos.

No Brasil, o circo surgiu no século XIX, com famílias advindas da Europa que manifestavam sua arte em apresentações teatrais. Contudo, as manifestações artísticas exigiam uma nova organização do circo, já que a migração de artistas "foi marcada pelas relações singulares estabelecidas com as realidades culturais e sociais específicas de cada região ou país" (SILVA; ABREU, 2009, p. 25). Assim, o circo se adaptou às linguagens e às diferentes culturas do país, tornando-se um espetáculo artístico muito importante, abrangendo um público significativo, assemelhando-se até mesmo ao cinema nacional (SILVA; ABREU, 2009).

A partir das décadas de 1940 e 1950, o crescimento urbano e a expansão do circo levou a arte de entreter para outra direção, deixando de ser apenas um espetáculo familiar para tornar-se uma empresa. Sobre isso, Silva e Abreu (2009, p. 27) atestam: "iniciou-se um processo de transformação do modo de organização do trabalho e do processo de socialização, formação e aprendizagem, alterando-se a transmissão dos saberes circenses, o que fez gerar outras formas de produção do espetáculo e do artista”.

Tal processo foi vivenciado não apenas com a família circense, mas com todas as famílias. Os saberes circenses, ainda passados de geração para geração, sofreu mudanças significativas nesta relação de troca de conhecimentos, e parte disso se deu com a obrigatoriedade da educação formal, essa que nas décadas de 30 e 40, estava em debate no Brasil. Os circenses por fazerem parte dos trabalhadores do Brasil e se preocuparem com o fato de seus filhos terem acesso à escola, buscaram adaptar-se à educação formal e não somente com a "formação de lona", como era até então (SILVA; ABREU, 2009).

\section{SENHORAS E SENHORES, GOSTARIA DE LHES APRESENTAR O ACESSO DA CRIANÇA À EDUCAÇÃO FORMAL COMO PROCESSO HISTÓRICO-SOCIAL}

A educação é um processo que acontece de variadas formas. $\mathrm{Na}$ antiguidade primitiva, acontecia de forma assistemática, mas, se analisarmos, ainda hoje nos deparamos com uma educação sob esta forma, quando levamos em consideração que a mesma não se 
limita ao ambiente escolar, já que a educação está por toda parte. Saviani (1980) define a Educação como um processo cujo caráter mediador se dá no seio da prática social global, ou seja, sua natureza é de constante aprendizado, independente do espaço, seja em nossa casa, em instituições diversas ou na escola estamos sempre aprendendo em nossas interações sociais.

Assim, podemos dividir a educação em: 1) não-formal “[...]aquela que se aprende no mundo da vida, via os processos de compartilhamento de experiências, principalmente em espaços de ações coletivos cotidianos" (GOHN, 2010, p. 16); 2) formal, cuja natureza institucional possui objetivos claros e específicos, representada principalmente pelas escolas e universidades (GADOTTI, 2005); 3) e por fim, a informal é a educação dada por meio de vivências, sem intencionalidades, compreendida "por não ser organizada, mas casual e empírica, exercida a partir das vivências e com base no bom senso" (ARANHA, 1990, p. 56). Em consonância a Saviani (1980), Gohn (2010) defende a despolarização dos tipos de educação, para que essa diversidade promova articulação de saberes. Ou seja, se faz necessário a integração de todos os tipos de educação, uma vez que, cada forma de manifestação carrega consigo valores, sentimentos e culturas, que são herdados pelos indivíduos e os ajudam na construção de sua identidade individual e coletiva.

É importante salientarmos que embora tenhamos várias formas de conceber a educação em nossa vida, ela remete-nos automaticamente à escola, espaço lócus da educação formal, instituição histórica de suma relevância para o funcionamento da sociedade, desde sua fundação até os dias atuais. Todavia, a escola não pode desconsiderar a historicidade do aluno, desprezando as outras formas de educação recebidas ao longo de sua vida. Essa atenção à história e à particularidade do estudante é crucial, tendo em vista o espaço importante da escola na sociedade e a multiplicidade de valores por ela instituídos ao longo do processo educativo.

É sabido que o acesso à educação formal nem sempre foi um direito, muito menos ele era extensível às distintas classes sociais, tal acesso está ligado à construção social dada às concepções de criança e infância ao longo do tempo. E nesse processo de transformação, mediante mobilização pública e científica, a educação formal transformou-se em um direito constitucional, direito de todos, como mostra a Constituição Federal em seu artigo 205, 
(BRASIL, 1988, p. 107 ) "A educação, direito de todos e dever do Estado e da família". Assim, a escola de um espaço para poucos, transformou-se em um espaço para todos, e também no "espaço primeiro e fundamental da manifestação da diversidade" (FRIAS; MENEZES, 2009, p. 09).

A diversidade é um aspecto relativo à valorização da multiplicidade de modos de existência, o que demanda a necessidade de descortinar os interesses daqueles que estão no seio da escola, a saber a criança e o jovem.

Rousseau, anterior ao século XIX, já apontava uma visão diferenciada, centralizando os interesses pedagógicos na criança, o que comprova a importância de cuidar e dar atenção à criança, algo inexistente na sociedade medieval (ARIÈS, 1986).

Registros históricos apontam que a acepção de criança como um ser social, é lenta e gradual (ARIÈS, 1986; ARANHA, 2006). Seu lugar na sociedade é reconhecido a partir dos avanços científicos quando "novas ciências, como a Psicanálise, a Pediatria, a Psicologia, consagraram-se aos problemas da infância, e suas descobertas são transmitidas aos pais através de uma vasta literatura de vulgarização" (ARIÈS, 1986, p. 276). Assim, a criança, deixa de ser vista como um mini adulto, uma tábula rasa, uma folha de papel em branco, para tornar-se um ser histórico e com capacidade de modificar a si mesma, sem dúvida, sua existência é essencial para o desenvolvimento humano e a qualidade da infância é de suma importância para se ter uma sociedade saudável.

Com isso, a escola toma um rumo diferente de sua criação, os castigos físicos deixam de existir, e as crianças e jovens começam a ter uma formação social, acadêmica e psicológica, vários movimentos sociais foram desencadeados em função de preservar e defender a criança e a sua infância, dentre as legislações criadas, podemos citar a lei considerada um marco na proteção da infância, o Estatuto da Criança e do Adolescente (ECA), lei de ${ }^{0} 8.069$ que entrou em vigor em 1990, tendo como base a proteção integral da infância. 


\section{EIS QUE SURGE NO PICADEIRO A CRIANÇA CIRCENSE!}

Todo contexto histórico descrito anteriormente foi importante para melhor compreendermos a protagonista desta pesquisa, a criança e o jovem, mais especificamente a criança circense, essa que assim como todas as crianças é um sujeito social e histórico. Todavia, quando falamos deste estudante em relação a seu acesso à educação formal, faz-se necessário uma reflexão maior, posto que, por se tratar de uma criança ou jovem na situação de itinerância, suas demandas são singulares e requer uma atenção diferenciada. Portanto, as frequentes mudanças de cidade e, consequentemente de escola, tornam-na em uma criança/jovem com necessidade de uma educação diferenciada. Segundo a Declaração de Salamanca (1994, p. 6) "Necessidades educativas especiais refere-se a todas as crianças e jovens cujas carências se relacionam com deficiências ou dificuldades escolares". Ainda sob a luz da Declaração de Salamanca (1994, p. 6), cabem as escolas "ajustar-se a todas as crianças, independentemente das suas condições físicas, sociais, linguísticas ou outras".

Nem sempre esse ajuste da escola aos estudantes é simples, como bem pontuamos, a escola nem sempre foi um espaço de inclusão, e sim por diversas vezes de exclusão, dado que a escola era para poucos (ÁRIES, 1986). E quando falamos do acesso da criança circense à educação formal, não é diferente, ao longo dos anos vários percalços existiram e existem em relação ao ensino e à educação de qualidade. Esses percalços são expressos na relação entre a construção de saberes circenses e o acesso ao saber formal, reconhecer essa relação é fundamental para a construção da identidade da criança circense.

O saber circense era repassado de geração à geração através da oralidade, tais saberes "davam conta da vida cotidiana, capacitação e formação dos membros do grupo" (SILVA; ABREU, 2009, p. 25), essa tradição da arte circense se mantém atualmente. O saber transmitido era suficiente para o aprendiz armar e desarmar o circo, preparar números teatrais, bem como ensinar outras crianças a executar as atividades (SILVA; ABREU, 2009). O conjunto de saberes advindo do circo constitui a educação não-formal e informal, estas são a base da construção identitária da criança, porém, negar a ela o acesso a outras formas de conhecimento é negar potencialmente o seu desenvolvimento. 
Dessa maneira, entra em cena o saber formal como "instância educativa que trabalha com o desenvolvimento do educando" (LUCKESI, 2011, p. 145). Segundo Silva e Abreu (2009) poucos foram os circenses que frequentaram a escola antes da década de 30. É importante ressaltar que nesse período não existia uma lei que assegurasse esse direito, sendo assim, quando esses frequentavam a escola era como ouvintes ou se deslocavam para casa de parentes com moradia fixa, longe dos espetáculos circenses. O governo de Getúlio Vargas trouxe algumas mudanças em relação ao acesso à educação formal dos circenses, em 1948, surge a Lei de $\mathrm{n}^{\circ}$ 301, como relata Silva e Abreu em seu livro Espetáculo Circense (2009, p. 163): "Importante é assinalar que os circenses, como boa parte dos trabalhadores brasileiros, também partilham do imaginário popular sobre Getúlio Vargas, o "pai dos pobres”, o "justiceiro", que teria feito a lei que "obrigava" as escolas a aceitarem filhos de gente de circo".

Contudo, a referida lei, apenas entrou em vigor no mandato de Eurico Gaspar Dutra, esta que dispunha sobre matrículas nas escolas primárias para os filhos de artistas circenses, ressaltando que esses podiam matricular seus filhos em escolas públicas ou particulares mediante o comprovante de matrícula da última instituição a qual havia passado. Isso foi um grande avanço, porém ainda falho, uma vez que se exigia a obrigatoriedade do documento de comprovação de matrícula, algo que nem sempre acontecia, diante do fato das crianças circenses frequentarem as escolas como ouvintes, não tendo assim sua matrícula efetivada.

É importante ressaltarmos que embora houvesse inúmeras dificuldades no acesso das crianças circenses à instituição escolar, nada impedia que as famílias circenses alfabetizassem suas crianças, "seja nas escolas públicas, contratando pessoas (professores ou não) para ir até o circo, levando suas crianças a espaços informais para aulas particulares, entre outros" (SILVA; ABREU, 2009, p. 165).

Ainda percorrendo nos caminhos das dificuldades do acesso à educação formal enfrentado pelos circenses, podemos destacar como esperança de mudança os avanços na legislação brasileira em oferecer o acesso formal para os artistas de vida itinerantes. Em 1978, entrou em vigor a Lei de $n^{\circ}$ 6. 533 que dispõe sobre a regulamentação das profissões de artistas e de técnico em espetáculos de diversões. Em seu art. 29 trata especificamente do acesso à educação formal dos filhos de artistas, cujas atividades são itinerantes, "terão 
assegurada a transferência da matrícula e consequente vaga nas escolas públicas locais de $1^{\circ} \mathrm{e}$ $2^{\circ}$ graus, e autorizada nas escolas particulares desses níveis, mediante apresentação de certificado da escola de origem" (BRASIL, 1978, p. 4). Além das leis já citadas para aqueles em situação de itinerância, temos a nossa constituição cidadã de 1988 que nos garante, independentemente de qualquer situação social, a educação como um direito de todos (BRASIL, 1988).

Após a obrigatoriedade da educação formal, a presença da criança circense na escola deixou de ser apenas um desejo dos pais de ofertarem uma educação de qualidade para seus filhos, e tornou-se uma obrigação para os mesmos. Porém, as dificuldades existentes nesse acesso à educação formal não mudaram simplesmente por se tornar obrigatório e de direito, crianças e adolescentes pertencentes a diferentes grupos sociais necessitavam e necessita de uma educação diferenciada, devido às constantes mudanças de escolas. No caso, da criança e jovem circense a situação de itinerância é definida por razões culturais, daí a responsabilidade político-social para com esses sujeitos (SILVA; GUEDES e RODRIGUES, 2016).

Diante disso, além das leis que já dispomos, tais como: a Constituição (1988), LBD (1996), ECA (1990), que trazem o acesso à educação formal como um direito do cidadão, os circenses dispõem de leis específicas para sua situação de itinerância, como o Parecer CNE/CEB n $n^{0} 14 / 2011$, relacionado às diretrizes para o atendimento de educação escolar de crianças, adolescentes e jovens em situação de itinerância. Outro importante documento é o projeto de lei $\mathrm{n}^{\mathrm{o}} 3.543$ - A de 2012, que regulamenta as profissões de artistas e técnicos em espetáculos, esta que veio alterando a Lei $\mathrm{n}^{\mathrm{o}} 6.533$ de 1978, incluindo como ponto principal "eliminar a possibilidade de recusa arbitrária e os entraves burocráticos que têm impedido a matrícula das crianças e jovens circenses na educação básica obrigatória" (BRASIL, 1978, p. $3)$.

Reconhecemos a importância do acesso à educação formal, porém mais importante do que estar na escola é receber uma educação de qualidade. A criança circense precisa de uma prática pedagógica voltada para suas necessidades específicas, isso implica em uma práxis direcionada, organizada "para concretizar determinadas expectativas educacionais" (FRANCO, 2015, p. 604). Para explicitar melhor, a criança circense, diferente das demais crianças, não frequenta apenas uma escola durante o ano, sua rotatividade nos espaços 
escolares, com um número considerável de professores a coloca num contexto distinto, que, muitas vezes, pode atrapalhar a construção de sua aprendizagem, visto os diferentes métodos de ensinos e os diferentes contextos escolares, aos quais ela é submetida. Diante disso, cabe à escola e aos profissionais que a formam, fazer com que o estudante, criança e jovem em formação, sinta-se parte desse contexto, buscando aliar ao ensino formal práticas significativas.

Compreendemos que uma prática significativa requer, nas palavras de Luckesi (2011, p. 140) "estar interessado em que o educando aprenda e se desenvolva, individualmente e coletivamente". Sendo assim, o educador precisa estar atento ao aluno para o desenvolvimento de uma prática educativa efetiva. Relacionando essa acepção à criança circense, cujo histórico de vida pressupõe uma cultura existente e todas suas particularidades escolares, é fundamental uma prática atenta ao seu desenvolvimento, no pequeno período que essa criança faz parte da turma. Pois é preciso levar em consideração seu modo de vida, suas diferenças e também suas potencialidades, visto que "uma aula só se torna uma prática pedagógica quando ela se organiza em torno: de intencionalidades, de práticas que dão sentido às intencionalidades [...]" (FRANCO, 2015, p. 605) configurada por uma ação consciente e participativa que leva em conta os sujeitos.

O que queremos indicar é a necessidade de um acompanhamento efetivo que vise o desenvolvimento da criança, para tanto é necessário que o educador tenha consciência em que ponto a criança está, em outras palavras, identificar o seu nível de aprendizagem, seus interesses, para então escolher onde pretende-se chegar, a fim de promover um acompanhamento efetivo e uma aprendizagem significativa. Luckesi (2011) defende a importância da assimilação de conteúdos decorrer a partir da recepção de informação em correlação à assimilação ativa, esta deve ser feita pela criança, por meio de exercícios que organizam a sua experiência. O direcionamento desse trabalho se sustenta através do acompanhamento efetivo com vistas ao aprofundamento da aprendizagem.

Nesse sentido, é imperioso lembrar que essa criança carrega consigo sua história, sua cultura e essa precisa ser preservada e respeitada, contudo, dificuldades são geradas em função das frequentes mudanças de cidade, e, consequentemente de espaço escolar. Isso torna a vida escolar desafiadora, dada a necessidade dos ajustes necessários a essa dinâmica. 
Independente das condições sociais, os ajustes a todas as crianças devem ser efetuados (BRASIL, 1994). A adaptação ao novo espaço não pode vir por parte da criança e do jovem que já lida com mudanças ocasionais, os diversos conteúdos e métodos de ensino e as diferentes pessoas ao longo do processo educativo formal. Porquanto, é preciso que a escola seja acolhedora, que os currículos sejam revisados às suas necessidades educativas especiais, que os educadores sejam mediadores nesse processo de desenvolvimento do estudante, tornando-o um ser autônomo e crítico de sua realidade social.

No entanto, a título de ilustração, quando refletirmos sobre os desafios relacionados às particularidades educativas da criança circense é preciso analisar sobre a prática e como a mesma influencia no processo de ensino aprendizagem desta criança. Portanto, segundo Silva, Guedes e Rodrigues (2016, p. 2127) “o processo de alfabetização, da criança circense necessariamente precisa ser adaptado ao contexto social para que aconteça de maneira significativa", e para que haja essa significação na aprendizagem, é preciso práticas pedagógicas que contemplem a realidade social e cultural deste estudante.

Em nossas argumentações, defendemos que a criança circense tenha acesso a uma prática pedagógica diferenciada, de modo a ajudá-la no processo de ensino-aprendizagem, para que a mesma possa aprender no curto período em que está na escola. Considerando a sua situação de itinerância, bem como o fato de a cada escola matriculada, ela passar por um processo de adaptação e socialização com a escola e os colegas de sala, é fundamental que os educadores reflitam como proporcionar um ensino de qualidade oriundos deste contexto. Cientes de que "a educação como prática social histórica, transforma-se pela ação dos homens e produz transformações nos que dela participam" (FRANCO, 2015, p. 608), é fundamental que a criança possa estar preparada para o pleno exercício da cidadania e adquirir conhecimentos, habilidades e valores que possam auxiliá-la em sua atuação na sociedade.

Através disso, faz-se necessário trabalhar conteúdos que contemplem a realidade desta criança ou mesmo jovem, como forma de contribuir na construção de sua identidade e aprendizagem. Tendo em vista que a escola funciona como um fio condutor, nesse processo de união e orientação acerca da construção da identidade do indivíduo (CARVALHO, 2012), e partindo dessa premissa "a missão da escola deverá, portanto, ser a de socialização e 
humanização dos sujeitos, na perspectiva de colaborar para que esses aprendam a aprender na convivência com os outros" (VERDUM, 2013, p. 93).

Acreditamos que a prática pedagógica efetiva deve basear-se em princípios de mediação entre o indivíduo e o meio (LUCKESI, 2011), para que haja a aprendizagem necessária ao educando, a escola e, principalmente, o professor que recebe o circense, devem ter um olhar diferenciado e um ensino intencional de modo a fazer com que essa criança sintase parte do ambiente ao qual está inserido. De modo semelhante, o contexto social e cultural do estudante pode contextualizado na escola. Pelizzari, Kriegl et al. (2002) seguindo as ideias de Ausubel, ao discorrer sobre aprendizagem significativa propõe a valorização dos conhecimentos prévios dos alunos: "para que possam construir estruturas mentais utilizando como meio, mapas conceituais que permitem descobrir e redescobrir outros conhecimentos, caracterizando, assim, uma aprendizagem prazerosa e eficaz" (PELIZZARI; KRIEGL et al., 2002, p. 01)

A partir dessa reflexão, vemos a importância do professor em sala na valorização das vivências adquiridas pelas crianças, pois "o processo ensino-aprendizagem torna-se eficaz, a partir do momento que o professor procura o desenvolvimento de suas atitudes, habilidades e conhecimentos a respeito das mudanças e inovações que se fazem necessária." (KLAUSEN, 2015, p. 6407). Ou seja, o professor tem um papel importante em dar, ou melhor, promover significado ao processo de ensino e para isso faz-se necessário a busca constante em aprender, e assim poder inovar sua prática pedagógica, de modo a atender as particularidades existentes em sala, pois o significado da prática educativa tem sua relevância quando associada às vivências dos alunos.

\section{DO PICADEIRO À ESCOLA: CAMINHOS METODOLÓGICOS}

Os procedimentos metodológicos partem da pesquisa exploratória e descritiva consultando obras que compilam a concepção de educação, em suas diferentes instâncias, e sua relação com a Educação Infantil, bem como à cultura circense (MARCONI; LAKATOS, 2008). 
Aliamos a esse levantamento histórico a pesquisa de campo a fim de buscar “informações e/ou conhecimentos acerca de um problema para o qual se procura uma resposta" (MARCONI; LAKATOS, 2008, p. 69). Nesse sentido, a entrevista semiestruturada (GIL, 2012) com os pais de crianças e jovens circenses, proporcionou uma melhor compreensão do contexto social e cultural no qual viviam.

A pesquisa de campo se deu por meio de entrevista semiestrurada, realizada em dois circos do agreste pernambucano, nomeadamente, Circo A e Circo B, situados nos municípios de Garanhuns-PE e Saloá-PE ${ }^{4}$. Sendo assim, todas as análises foram pautadas nos dados construídos a partir das visitas aos dois circos que tinham crianças/jovens matriculados em escolas $^{5}$, para descrever o acesso à educação formal desses estudantes, e melhor compreender o contexto das relações envolvidas nesse processo.

O instrumento para a construção dos dados foram a entrevista semiestruturada e o questionário. Partiu inicialmente da entrevista semiestruturada "técnica em que o investigador se apresenta frente ao investigado e lhe formula perguntas, com o objetivo de obtenção dos dados que interessam à investigação" (GIL, 2012, p. 109), efetuadas com os pais de crianças circenses. Conforme Gil (2012, p. 110) destaca esse instrumento metodológico, "possibilita captar a expressão corporal do entrevistado, bem como a tonalidade de voz e ênfase nas respostas", de modo que torna a interação entre investigador e investigado mais humana, não se limitando apenas a respostas diretas, mas proporcionando o surgimento de outras perguntas ao decorrer da entrevista.

No circo B, entrevistamos um pai, este acompanhado de seus dois filhos pequenos e uma filha adolescente, todos matriculados em escolas. No circo A, entrevistamos uma mãe, esta acompanhada de sua filha também matriculada. Em ambas as entrevistas as perguntas

\footnotetext{
${ }^{4}$ Inicialmente, a visita de campo se deu em três circos, sendo dois na cidade de Garanhuns/PE e o outro na cidade de Saloá/PE, porém, apesar de termos ido a três circos, apenas em dois pudemos colher os dados para pesquisa, diante do fato de um dos circos visitados não constar criança ou jovem em idade escolar.

${ }^{5} \mathrm{O}$ circo A, em turnê no município de Garanhuns-PE, continha três crianças filhos de artistas circenses, porém apenas uma criança estava matriculada na escola. No circo B, situado no município de Saloá-PE, havia seis crianças e um jovem de 17 anos, todos estavam matriculados. De forma pragmática, optamos por entrevistar um responsável de cada circo.
} 
eram as mesmas. As questões permearam temáticas relacionadas ao acesso à escola ${ }^{6}$; ao número de escolas em que a criança se matriculou durante o ano letivo; à socialização/interação e à adaptação; ao material didático; aos fardamentos; ao processo de ensino-aprendizagem, dentre outras que foram surgindo no decorrer da entrevista.

Ao longo da entrevista, os estudantes por vezes participavam da conversa e, embora o nosso foco respaldasse nos registros narrativos dos responsáveis, há falas interessantes que retratam os sentimentos dos estudantes e integram à análise que segue.

Todas as entrevistas foram gravadas, registradas e transcritas, de modo a serem utilizadas na coleta de dados da pesquisa, sempre buscando respeitar as falas dos entrevistados, bem como sua identidade. Para tanto, nas análises descrevemos as falas como circo A e circo B, referindo-se a ambos os circos pesquisados ${ }^{7}$.

A partir das transcrições, adotamos a orientação de Severino (2007) quanto aos procedimentos de análise interpretativa, com base em referenciais teóricos visitados, histórias das educações e de legislações vigentes, e nos dados construídos a fim de discutir as unidades de registro encontradas.

Diante das falas registradas e transcritas, de forma complementar, dispomos de outra técnica de investigação, o questionário, este composto por questões aplicadas com o propósito de obter informações (GIL, 2012) sobre as políticas do município para receber as crianças circenses. Nossa intenção baseou-se em buscar inferências nas falas emitidas pelos pais para compreender as condições contextuais do município. Assim, aplicamos para a diretora de ensino do município de Garanhuns, um questionário composto por cinco perguntas: 1) Ao se deparar com a chegada de uma criança ou jovem em situação de itinerância, a escola envia

\footnotetext{
${ }^{6} \mathrm{O}$ roteiro prévio apresentou perguntas semiabertas, tais como: 1) Quantas crianças/jovens tem no circo e quantas frequentam a escola?; 2) Quantas escolas, em médias a criança muda por ano?; 3) Quantos dias costumam ficar em cada escola?; 4) Como elas são recebidas pelas instituições?; 5) Como acontece o ato da matrícula?; 6) Elas recebem material didático e fardamento?; 7) Como é o tratamento do professor?; 8) Como é a socialização da criança com os demais da turma?; 9) Elas se sentem excluídas por serem itinerantes?; 10) Existe alguma diferença de tratamento entre as escolas públicas e privadas? 11) Existe algum relatório avaliativo que é repassado de escola para escola, com as informações das aprendizagens das crianças?

${ }^{7}$ Apesar de nossa pesquisa implicar o levantamento de características relacionadas à educação da criança do circo, não a classificamos como estudo de caso em virtude de nossas limitações de observação mais sistêmica, como por exemplo, acompanhar o indivíduo na escola. Nossa pesquisa, apesar de particular, não nos possibilitou o conhecimento da realidade das crianças circenses de forma aprofundada.
} 
algum histórico desse estudante para a secretaria de educação?; 2) Existe alguma prática pedagógica direcionada para atender a especificidade da criança circense? Se sim, quais?; 3) Como a secretaria e a escola acompanha o desenvolvimento dessa criança?; 4) Como se dá a socialização dessa criança na escola? Existe algum acolhimento diferenciado?; 5) Quais as principais dificuldades relacionadas à matrícula da criança circense? Devido à indisponibilidade presencial da Diretora de ensino em ser entrevistada, lançamos mão do questionário, o qual foi aplicado via e-mail.

Embora a pesquisa tenha como sujeito de pesquisa a criança circense, durante a pesquisa de campo, nos deparamos com outros sujeitos: o adolescente circense e a criança circense com deficiência, sujeitos estes que se entrelaçam na pesquisa, por fazerem parte deste contexto de itinerância e por também enfrentarem percalços relacionados ao seu acesso à educação formal e todas as particularidades existentes neste contexto.

Dessa maneira, os procedimentos analíticos seguem uma análise interpretativa, mediante os registros instrumentais: entrevista e questionário, como forma de compreendermos como se dá o acesso à educação formal da criança circense, bem como de analisarmos as particularidades educativas desta criança neste acesso.

\section{A VOZ DOS CIRCENSES: REFLETINDO SOBRE O ACESSO E OBSTÁCULOS EDUCACIONAIS}

Após as entrevistas de acordo com a visão dos pais em relação ao tratamento escolar dado aos seus filhos, surgiram alguns pontos que julgamos pertinente a discussão dos mesmos, tais como: acesso à educação formal, fardamento, material didático, acompanhamento do estudante, dentre outros pontos que foram surgindo no decorrer das entrevistas.

Em relação ao acesso à educação formal, relatamos nos dados obtidos da criança circense, que, embora a educação formal seja um direito adquirido por lei na Constituição de

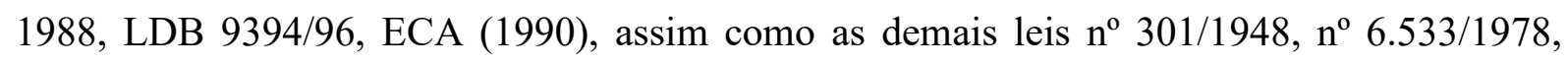
específicas para os estudantes filhos de pais em situação de itinerância, como o parecer 14/2011 e o projeto de lei $n^{0} 3.543$ - A (2012), atualmente, os pais ainda enfrentam 
dificuldades no momento de matricular seus filhos em algumas escolas em nosso país. Essa é uma situação vivenciada pelo pai entrevistado. O acesso à educação formal tem como "porta de entrada" o ato da matrícula, sobre as dificuldades referente à matrícula de seus filhos o pai, do circo B menciona:

Muita, muita, no Cabo de Santo Agostinho, eles estavam com, estavam com, como diz, no Cabo estava tendo prova, na época de prova segundo bimestre, tudo, e quando ela chegou lá nenhuma escola aceitou eles, nenhuma escola, e a gente, mostrou, falou que tinha a lei, mas é assim, não... está em período de prova eu não vou botar o menino aqui e na época eles não estudaram no Cabo em nenhuma escola (PAI - CIRCO B, 18/08/2018).

A fala do pai descreve a recusa das escolas no momento de matricular seus filhos, mesmo este citando a lei que lhe garante o direito. É importante refletir que ainda que não houvesse uma lei específica para pessoas em situação de itinerância, a criança circense já estaria assegurada pela constituição em seu art. $6^{\circ}$ no que diz respeito aos direitos sociais do cidadão, esse que são direitos sociais à educação, à saúde, à alimentação e etc. (BRASIL, 1988 , p. 6 ), bem como no art. 206 em relação aos princípios do ensino, determinando "igualdade de condições para o acesso e permanência na escola", ou seja, não faz sentido a recusa dessas crianças, qualquer que seja a situação, pois a educação é um direito de todos os cidadãos.

Esse é o primeiro entrave em relação ao acesso à educação formal enfrentados pelos pais e crianças circenses. Após a matrícula outros percalços são enfrentados pelos circenses, quais sejam, fazer com que o período em que a criança circense esteja na escola, exista uma aprendizagem significativa e que a criança se sinta parte deste contexto. Historicamente, como bem cita Ariès (1986) a escola é lugar para poucos, tal afirmação é uma constante nos dias atuais, mesmo com todo avanço relacionado à inclusão, a escola exclui mais que inclui, e para contextualizarmos, trazemos as falas dos pais entrevistados em relação à distribuição de material didático e ao fardamento para seus filhos na escola.

... tem escola que ela recebe, mas tem escola que não, tem escola que não tem pronto. Na escola que ela está aqui, ela recebeu a bolsa, os lápis e a farda, só a parte de baixo, que a de cima não tinha só o shortinho, e a de cima não tinha. (MÃE CIRCO A, 25/06/2018)

A primeira cidade que meu filho recebeu fardamento foi aqui, aqui os dois receberam na mesma hora, ela recebeu também na mesma hora, porque ela é no EREM, eles deram duas fardas pra ela e eles receberam uma farda cada um. Agora, material didático não. O maior (Referindo-se ao filho mais velho)... as professoras 
deram pra ele uns livros, mas não são livros novos não, são livros que elas deram pra ele mesmo. Não é o que o pessoal está usando. (PAI - CIRCO B, 18/08/2018)

É porque também é assim: vai no colégio é um livro, vai em outro, é outro, vai em outro, é outro livro, então ele nunca tem um livro, ele vai pro colégio, vai pro colégio senta, as professoras vai dando aula pra quem tem livro e ele fica só assistindo aula (PAI - CIRCO B, 18/08/2018)

Podemos notar em ambas as falas dos entrevistados uma exclusão por parte das políticas públicas em orientar as escolas em garantir que essas crianças sejam tratadas com igualdade perante os demais. Isso ocorre em situações bem pragmáticas, tais como o fardamento escolar e o material didático. Em se tratando do fardamento escolar, nem sempre as escolas disponibilizam para os estudantes circenses. De modo similar, ao refletirmos especificamente em relação ao livro didático, este nem sempre é distribuído e quando isso acontece, não é o mesmo que a turma está estudando naquele dado momento, como relatou o pai entrevistado "as professoras deram pra ele uns livros, mas não são livros novos não, são livros que elas deram pra ele mesmo. Não é o que o pessoal está usando”. Ele continua:

O que eu acho também mais complicado é por causa desse negócio de livro, que num disseram que iam fazer esse ensino. É.., que está passando na televisão (Neste momento, o entrevistado refere-se à BNCC). (PAI - CIRCO B, 18/08/2018).

As crianças circenses mudam de escolas por diversas vezes, sendo esta uma das particularidades educativas das crianças circenses que dificulta o seu processo de ensinoaprendizagem. Assim, relata a mãe "ela passa no máximo 15 dias na escola, às vezes passa um mês quando a gente passa na praça, eu não sei/ quanto tempo mesmo" (MÃE - CIRCO A, 25/06/2018), e na fala do pai (PAI - CIRCO B, 2018), quando informa que até a data presente da entrevista as crianças "já haviam mudado oito vezes de escolas", sendo assim faz-se necessário uma preocupação com a aprendizagem dessa criança desde a sua chegada à escola até o término de sua estadia nela.

Além das diversas escolas ao longo do ano e do pouco período em que o estudante permanece em cada escola, é importante refletirmos sobre o período que essa criança fica fora da sala de aula. Calculando a soma do período de deslocamento entre uma cidade e outra, do período de montagem do circo, além da procura da escola, teremos um número considerável de dias longe da escola. Essa ausência deve ser compensada nos dias em que a criança e o jovem estiver em condições de frequentar à escola, algo que nem sempre acontece, evidenciando assim mais um fator de entrave no processo de aprendizagem dessas crianças. 
Às vezes eu, nós vai se mudar e não dá tempo de fazer matrícula dela, a ela passa dois a três dias sem tá na aula, por conta que a gente tá mudando os trailers, mudando o circo, aí não dá tempo de levar ela, aí sempre ela começa com dois, três depois que nós chega no terreno. (MÃE - CIRCO A, 25/06/2018)

Uma vez matriculados e estudando em sala de aula, a presença do aluno em sala não é garantia de aprendizagem. O processo de ensino-aprendizagem vai muito além do período de permanência na escola, ele está ligado à qualidade do que se aprende neste período. Para tanto, é preciso uma prática pedagógica diferenciada e significativa a essas crianças que permanecem por pouco tempo na sala de aula. Durante as entrevistas semiestruturadas, quando dialogamos sobre as práticas específicas relacionadas ao acompanhamento de atividades, o que obtivemos foram relatos de atividades realizadas seguindo uma continuação de cadernos anteriores, não há nenhum relatório sobre o desenvolvimento do aluno, o que acaba dificultando para que o professor seguinte possa acompanhar o desempenho das crianças. A respeito disso, quando perguntado se existe algum relatório de acompanhamento de desenvolvimento a jovem que acompanhava o seu pai interviu, respondendo: "Não, eu levo o assunto e mostro aos professores o que eu estava tendo" (JOVEM-CIRCO B, 18/08/2018).

Essa é uma situação similar descrita pela mãe de uma criança circense do circo A:

Sempre quando ela, por exemplo, esse ano né, ela está estudando, aí ela tira de uma escola para outra, aí ela vai com o mesmo caderno, que ela está na escola, ela vai pra outra, e continua a continuidade das tarefas dela, pra não bater outras tarefas, por ela complica mais ainda. (MÃE - CIRCO A, 25/06/2018)

Observemos que independente do nível escolar, educação infantil ou ensino médio, não há medidas efetivas de acompanhamento acerca das temáticas curriculares, tampouco um relatório para servir de parâmetro na questão do desenvolvimento do estudante.

Acreditamos que a ausência desse relatório prejudica a aprendizagem do estudante, pois sem um procedimento específico, garantindo a educação da criança em um caderno de atividades de escolas anteriores, caderno este escrito pela própria criança, coloca essa criança como responsável pelo seu próprio ensino, se levarmos em consideração que não há garantias de que esta criança esteja de fato escrevendo e registrando todas as atividades das escolas anteriores.

No que refere ao acompanhamento desse estudante, podemos observar uma lacuna que não deveria existir se as escolas seguissem como prevê o parecer 14/2011 em seu artigo 30 "A instituição de ensino deverá realizar avaliação diagnóstica do desenvolvimento e da 
aprendizagem desse estudante, mediante acompanhamento e supervisão adequados às suas necessidades de aprendizagem”. Ou seja, a lei é muito clara, e se isso não está acontecendo, cabe questionar se esta criança está passando de uma escola para outra sem um acompanhamento efetivo realizado de forma sistêmica. Isso levanta outras questões: Como esta criança será avaliada ao longo de sua formação? Como seu desempenho será observado? Como o professor pode tomar medidas efetivas de avaliação agregando a essa prática a ação educativa.

Ainda sobre a importância de registrar o acompanhamento das crianças, no mesmo artigo em seu inciso $\mathrm{V}$, novamente a LDB destaca a obrigatoriedade de um registro "expedição de documentação que permita atestar os processos de desenvolvimento e aprendizagem da criança", e a ausência desse registro vem causando uma preocupação aos pais que se queixam do processo de ensino-aprendizagem de seus filhos. O pai de uma das crianças relatou o fato de seus filhos passarem de um ano a outro, o que validaria o aprendizado já que eles atingem as competências necessárias ao ano cursado, contudo, em casa seus filhos não conseguem ler, muitas vezes fazendo com que os responsáveis solicitem à escola a repetência dos filhos, na expectativa de um melhor desenvolvimento, "o colégio ele passa, mas aqui em casa ele não consegue ler nada, então eu o coloco pra voltar”. (PAI CIRCO B, 18/08/2018).

Outro fator importante observado foi em relação à adaptação das crianças, ambos entrevistados mencionaram que não tinham problemas relacionados a questões de socialização e adaptação de seus filhos pequenos, as crianças ao chegarem nas escolas são bem recebidas pelos professores e colegas de salas, bem como fazem amizade com facilidade, mas quando falamos da jovem, o pai relatou que a adolescente tem uma maior dificuldade de adaptação no início, desde as questões de amizades como alimentação, “ .... já é mocinha, é mais complicado a adaptação, ela está no EREM todos esses dias, o primeiro dia que ela veio comer lá no EREM foi ontem, eu falo (Jovem) almoça, ela tem vergonha” (PAI - CIRCO B, 18/08/2018). No entanto, em uma das falas, identificamos que embora a vida itinerante seja algo que faz parte da vida destas crianças e o processo de socialização é tranquilo, a hora da partida é diferente. Em uma das falas, a mãe aborda a dificuldade da criança em sair da escola e de perto de seus colegas, "ela sempre se dá bem com os alunos, até pra quando eu vou tirar 
ela, ela chora, - "mãe quero ir não para outra escola, não, quero ficar aqui meus amiguinhos é tão legal". (MÃE - CIRCO A, 25/06/2018).

Registramos ainda que os pais de crianças do circo A sempre procuram matricular seus filhos em escolas públicas, diferente dos pais de crianças do circo B que preferem fazer parcerias com as escolas particulares dos municípios, pois acreditam que em tais escolas o ensino é mais rígido, apresentando um ensino melhor, "a gente coloca em colégio particular, eles puxam muito e ajudam eles"(PAI - CIRCO B, 18/08/2018).

Interessante à menção do pai acerca da rigidez e do ensino de qualidade. Proporcionar uma educação eficaz, dentre inúmeros aspectos que poderíamos citar, implica o exercício da docência em desenvolver práticas efetivas e significativas, da qual fala Luckesi (2011), ou seja, inferimos aqui a necessidade de construir instrumentos mediadores que auxiliem a aprendizagem e a apropriação de sentidos e significados. A criança/jovem circense possui um histórico de aprendizagens artísticas na constituição de sua educação informal. E isso não pode ser desconsiderado quando pensamos nos sentidos construídos no processo de aprendizagem. O acompanhamento do estudante, com vistas à avaliação de sua aprendizagem faz parte de seu processo formativo. Essa é uma reflexão importante, quando consideramos as medidas de acompanhamento da prática pedagógica. Os pais, ao serem indagados sobre as práticas pedagógicas, afirmaram que:

É só o caderno que segue mesmo, e às vezes ele diz: ela saber ler? Fazer contagem? Aí eu respondo: ela não aprendeu isso, porque ela está no pré-2, mas como ela está passando para o primeiro ano agora, ai a diretora daqui até disse: "ela tá com idade do primeiro ano, a gente vai colocá-la no primeiro ano, se ela se desenvolver, ela fica no primeiro, se não ela volta pro pré-2. (MÃE - CIRCO A, 25/06/2018)

Quando ele vai pra um colégio particular, colégio particular avalia, insiste nele, a professora, de vez em quando, não é sempre não, a maioria do colégio quando vou fazer, porque eu vendo espetáculo pros colégios, quando eu entro no colégio está todo mundo escrevendo e eles dois sentados sem fazer nada, tem professora tem preguiça de colocar eles pra estudar. (PAI - CIRCO B, 18/08/2018).

Nas falas acima, podemos observar a inexistência de uma prática diferenciada para o estudante circense. Em nossa pesquisa, os pais apontaram que apenas em algumas escolas existe uma preocupação por parte dos professores em trabalhar com esses alunos, gerando muitas vezes atraso no processo de aprendizagem. Acreditamos que a prática diferenciada levaria em conta a singularidade da criança circense, permitindo aí o acesso e permanência no 
ambiente escolar de forma minimamente satisfatória. Todavia, é importante ressaltar que embora a legislação vigente exista, parecer 14/2011, nem sempre ela é cumprida, não por culpa da escola ou professores, mas podemos destacar que falta gestão por parte dos órgãos governamentais que possam preparar esta escola e o corpo docente para receber essas crianças com suas especificidades, seguindo as falas dos entrevistados e confrontando com a resposta da secretaria de educação do município de Garanhuns/PE, em relação à pergunta: Existe alguma prática pedagógica direcionada para atender a especificidade da criança circense? A resposta obtida foi direta, "Não, necessariamente. Pois as salas de aula são bastante heterogêneas e os alunos que porventura chegam à escola, oriundas de circo, se matriculam, frequentam regularmente e quando o circo vai embora eles levam a transferência". (SEG, 21/09/2018), ou seja, isso só reforça o que mencionamos em relação à ausência de políticas públicas para que essas crianças possam de fato serem acompanhadas em suas necessidades educativas.

Outro ponto necessário à reflexão é sobre a inclusão, as dificuldades de acesso à educação formal se intensificam quando relacionado a crianças e jovens circenses com deficiência, como citado pelo entrevistado:

Tem um autista, ele também vai à escola, mas isso é uma coisa que as escolas do Brasil não estão preparadas para receber uma criança autista, é raro pegar uma cidade que tenha preparo para ensinar uma criança autista, não é todas que tem apoio não. (PAI - CIRCO B, 18/08/2018).

Dessa maneira, inferimos deste relato a negligência do sistema educativo em capacitar os agentes educativos para receber a criança autista, filho de um circense. O pai, representante do circo B, ao narrar sobre a permanência da criança autista na escola afirma:

Fica sem estudar, esse ano ele não foi para nenhuma escola, que as vezes você chega no colégio, fica no primeiro dia, no segundo a professora já manda vir buscar, porque não tem quem cuide dele, tem que ter uma pessoa especial pra ele, ai o colégio vai contratar uma pessoa, só pra cuidar dele, a escola não está preparada, ele atrapalha muitos as aulas, fica gritando muito, fica difícil. (PAI - CIRCO B, 18/08/2018).

Considerando essas particularidades, buscamos de forma complementar, uma compreensão mais abrangente de como ocorre a oferta da educação formal dessas crianças. Assim, recorremos à secretaria da educação de Garanhuns, por meio de um questionário. Em relação ao acompanhamento dado à criança em situação de itinerância, em específico à 
criança circense, obtivemos uma triste resposta sobre a seguinte pergunta: Como a secretaria e a escola acompanham o desenvolvimento dessa criança? "Não existe esse acompanhamento" (SEG, 21/09/2018). Segundo o questionário aplicado, não existe no município o cumprimento das políticas públicas de atendimento à criança em situação de itinerância que venha a acompanhar o desenvolvimento do mesmo. Como podemos observar, a fala da diretora de ensino legitima a falta de acompanhamento declarada pelos pais, fazendo com que essas crianças não sejam assistidas e acompanhadas em sua escolaridade, prejudicando-as em seu processo de aprendizagem, ao longo de sua formação.

Além da ausência de acompanhamento, observamos a falta de comprometimento do sistema educacional em contemplar a articulação com a educação não-formal aquela que se aprende a partir do compartilhamento de vivências, essa que (GOHN, 2010, p. 20) fundamenta como uma educação em "critérios da solidariedade e identificação de interesses comuns, parte do processo de construção da cidadania coletiva e pública do grupo", critérios esses ignorados pela escola, isso parece ocorrer em função do objetivo escolar ser institucional tecnicista e pouco atentar para aquela criança ou adolescente que sai do "padrão de aluno" perfil de aluno regular.

Diante do exposto, analisamos que inúmeras são as dificuldades encontradas pelos pais, crianças e jovens circenses em seu acesso à educação institucional, porém é importante ressaltarmos que pudemos observar, através da fala e dos gestos de um dos entrevistados o orgulho declarado da posição de um jovem circense que está na faculdade. Observamos então, o quanto a educação formal é importante para a sociedade e remete orgulho àqueles que a vivenciam. Essa assertiva foi identificada ao perguntamos sobre a escolaridade do entrevistado, este que informou "Fiz até o sexto ano" (PAI - CIRCO B, 18/08/2018), sua filha que estava ao lado tomou a palavra e mencionou: "aqui no circo já teve um que terminou com 16, ai tá fazendo faculdade, hoje ele foi fazer prova no Recife, ele faz a distância, ai quando marca prova ele vai pra Recife" (JOVEM - CIRCO B, 18/08/2018), seus olhos brilharam ao pronunciar estas palavras, seu gesto mostrava orgulho pela pessoa mencionada. 


\section{INCONCLUSÕES: A CORTINA NÃO PODE FECHAR}

Nesta pesquisa, procuramos compreender as particularidades educativas da criança circense em seu acesso e garantia de permanência à educação formal sob à ótica das famílias, e para refletirmos sobre, foram realizadas pesquisas bibliográficas, de campo com dois circos, A e B, e uma aplicação de um questionário junto à secretaria de educação do município de Garanhuns/PE. Os dados apresentaram particularidades educativas da criança circense em relação às diversas mudanças de escola durante o ano, bem como diversas dificuldades relacionadas ao seu acesso à educação formal, como: matrícula, fardamento, assim como práticas pedagógicas que não contemplam as particularidades da itinerância.

Identificamos a dificuldade dos pais matricularem seus filhos, ou seja, o acesso à escola já é um problema que muitos pais em alguns municípios e estados do nosso país precisam enfrentar, mesmo com leis que garantem esse acesso (BRASIL, 1988; BRASIL, 1994; BRASIL, 1996), conforme os pais relatam, nem todas as escolas cumprem com a lei. Inclusive observamos esse fato no munícipio de Garanhuns/PE, ao analisarmos o questionário aplicado à Secretaria de Educação do município.

Além da problemática de acesso, os pais reclamam da exclusão de seus filhos em relação à distribuição de livros didáticos, materiais escolares e fardamentos, nem todas as escolas disponibilizam esses materiais, e as crianças acabam sendo excluídas de alguns processos pedagógicos em sala, por não estarem com os livros didáticos corretos.

Ainda em relação à exclusão, é importante discutirmos sobre o fato da criança circense está em uma situação desigual em relação as demais crianças do ensino regular, mesmo com todo aparato legal da Constituição de 1988, da LDB 9394/96 e do parecer 14/2011 que garantem o acesso desta criança à escola. As circunstâncias que envolvem este acesso, colocam a criança/jovem em uma situação de exclusão social, devido a não ser possível desenvolver um acompanhamento sistemático do desenvolvimento desta criança ou adolescente circense.

Por estarem sempre interrompendo o ensino regular, a criança e o jovem acabam se deparando com vários percalços, como falta de acompanhamento efetivo, ausência de relatórios de avaliação, políticas públicas ao jovem circense, certamente ocasiona um índice 
de progressão mais lento, podendo dar margem inclusive à evasão escolar. Essa afirmação sobre progressão surgiu pelo fato da professora, segundo a fala do pai, não dar atenção à criança e ao jovem circense, isso indicia a possibilidade desses sujeitos serem vistos de forma estereotipada e de que são menos capazes de progredir. Esse aspecto pode ser melhor observado em pesquisa futura, como forma de acompanhar o estudante na sala de aula e verificar no dia a dia como essas crianças e jovens são tratadas no contexto escolar.

Buscamos verificar, a partir da ótica das famílias e suas vivências a existência de uma educação diferenciada para as crianças advindas do espaço circense, o que observamos é a inexistência de uma prática pedagógica diferenciada para esta criança, além de suas particularidades não serem consideradas dado o fato de a mesma estar sempre mudando de escola e necessitar de um olhar diferenciado por parte da escola e do professor para seu processo de ensino aprendizagem.

Observamos ainda, que além da falta de uma prática pedagógica voltada para o acompanhamento desses estudantes, falta cumprimento das políticas públicas existentes que garantem um escolaridade com qualidade para esses estudantes, por isso a importância de se pesquisar sobre a criança circense e suas especificidades em relação à educação formal, pois essas crianças estão nas salas de aulas e não são vistas em suas particularidades. Contudo, é importante ressaltarmos que essas são análises feitas sob a ótica dos entrevistados, esses que foram os pais, mães de crianças circenses.

Presenciamos nas falas dos entrevistados, muitas reclamações em relação aos filhos estarem atrasados nos estudos, estarem em idade para leitura e não saberem ler, bem como relatos dos pais sobre professores que têm preguiça de investir em um aluno que fica pouco tempo em sala. Assim, é urgente a mudança dessa realidade, faz-se necessário fazer a diferença nesse curto período em que a criança se encontra em sala, o que significa cumprir com as demandas mencionadas no parecer 14/2011 (BRASIL, 2011) e na LDB (BRASIL, 1996) de garantir matrícula, avaliação periódica mediante expedição e relatório.

A realidade das crianças circenses nos mostrou que são inúmeras as demandas educativas para uma educação formal de qualidade, porém mesmo com leis que lhes dão o direito a uma educação de qualidade, ainda existem muitos percalços que impedem que isso 
de fato aconteça, falta formação continuada para professores. Segundo o parecer 14/2011, é dever do Estado ofertar cursos de formação para esses profissionais, de modo que eles possam construir conhecimentos e repensar suas estratégias de práticas pedagógicas, considerando a reflexão e o reconhecimento do contexto histórico e as particularidades da criança. Dessa maneira, o trabalho de formação humana será atendido adequadamente e com responsabilidade pelo sistema educativo.

Além de formação para garantir uma prática pedagógica significativa para os alunos itinerantes, seria importante que o parecer 14/2011 fosse cumprido, pois o mesmo traz as diretrizes para que o atendimento escolar de crianças e adolescentes em situação de itinerância de fato seja eficaz. Com esse cumprimento efetiva-se o acompanhamento avaliativo, informando o desenvolvimento do estudante, dando a possibilidade de que as famílias possam entregar a cada escola um relatório ao matricular seus filhos. A avaliação periódica é fundamental para que os professores possam dispor de informações importantes para o desenvolvimento desses estudantes (BRASIL, 2011). Diante do exposto, o que podemos concluir é que embora a criança ou o jovem circense tenha diversas particularidades em sua vida escolar, no dia-a-dia não há nada de particular na forma como a mesma é acolhida em seu acesso à educação formal.

Dar voz à criança circense é refletir sobre a diversidade existente em nossas escolas, como forma de um melhor acolhimento e garantia de qualidade no ensino. Tal reflexão atentase ainda não somente à criança circense, mas a todas as crianças, de modo que as mesmas tenham seus direitos preservados, e que nenhuma criança seja excluída por sua condição social, cultural, econômica e etc.

Diante disso, esta pesquisa não finaliza a discussão, pois faz-se necessário estudos mais aprofundados nas demandas educativas das crianças circenses, de modo a acompanhar o seu cotidiano em sala de aula, para observar as práticas pedagógicas que a circundam, assim como analisar a adaptação e socialização desta criança ou adolescente na escola, buscando compreender através da observação quais sentimentos envolvem todas essas especificidades de mudar de escola por diversas vezes ao ano. Somente a pesquisa de situações particulares, como o olhar das famílias, dos estudantes, a visão dos professores em relação às demandas 
educativas dessas crianças pode, de fato, dar voz a uma educação diferenciada que contribua significativamente com a formação plena do estudante circense.

\section{REFERÊNCIAS}

ARANHA, Maria Lúcia de Arruda. Filosofia da educação. $2^{\circ}$ ed. São Paulo: Editora moderna, 1990.

ARANHA, Maria Lúcia de Arruda. História da Educação. $3^{\circ}$ ed. São Paulo: Editora moderna, 2006.

ARIÈS, Philippe. História social da criança e da família. $2^{\text {a }}$ ed. Rio de Janeiro: Guanabara, 1986.

BRASIL. Constituição da República Federativa do Brasil. Brasília, DF: Senado, 1988.

BRASIL. Câmara dos Deputados. Projeto de Lei $\mathbf{N}^{\mathbf{0}}$ 3543-A de 2012. Altera a Lei $\mathrm{n}^{\circ}$ 6.533, de 24/05/1978. Disponível em: < http://www.camara.gov.br/sileg/integras/980768.pdf>. Acesso em 19 de mar. 2017.

BRASIL. Declaração de Salamanca: Sobre Princípios, Políticas e Práticas na Área das Necessidades Educativas Especiais, Salamanca-Espanha, 1994.

BRASIL. Estatuto da Criança e do Adolescente. Brasília, Diário Oficial da União, 13 de julho de 1990.

BRASIL. Lei de Diretrizes e Bases da Educação Nacional - nº 9394/96, de 20 de dezembro de 1996, Brasília: MEC, 1996.

BRASIL. Lei no 301, de 13 de julho de 1948.

BRASIL. Lei $\mathbf{n}^{\circ} \mathbf{6 . 5 3 3}$, de 27 de maio de 1978 .

BRASIL. Parecer CNE/CEB no 14/2011, de 07 de dezembro de 2011.

BRANDÃO, Carlos Rodrigues. O que é educação. $1^{\text {o }}$ ed. São Paulo: Brasiliense, 2007.

CARVALHO, Mauro. A construção das identidades no espaço escolar. Revista Reflexão e Ação, Santa Cruz do Sul, v. 20, n1, p.209 - 227 jan./jun. 2012. Disponível em https://online.unisc.br/seer/index.php/reflex/article/view/2161 Acesso em 15 de novembro de 2017.

CASTRO, Alice Viveiros. O circo conta sua história. Museu dos teatros. Rio de Janeiro: FUNARJ, 1997.

FRANCO, Maria Amélia Santoro. Práticas pedagógicas de ensinar-aprender: por entre resistências e resignações. Educ. Pesqui., São Paulo, v. 41, n. 3, p. 601-614, jul./set. 2015. 
Disponível em < http://www.scielo.br/pdf/ep/v41n3/1517-9702-ep-41-3-0601> Acesso em 25 de novembro de 2019.

FRIAS, Elzabel Maria Alberton; MENEZES, Maria Christine Berdusco. Inclusão escolar do aluno com necessidades educacionais especiais: Contribuições ao Professor do Ensino Regular. 2009. Disponível em <http://www.diaadiaeducacao.pr.gov.br/portals/pde/arquivos/1462-6.pdf $>$ Acesso em 21 de março de 2018.

GADOTTI, Moacir. A questão da educação forma/não-formal. Droit à l'education: solution à tous les problèmes sans solution? Institut International des droits de l'enfant, Sion, 2005 .

GIL, Antonio Carlos. Métodos e técnicas de pesquisa social. 6. ed. São Paulo: Atlas, 2012.

GOHN, Maria da Glória. Educação não formal e o educador social. Atuação no desenvolvimento de projetos sociais. São Paulo: Cortez, 2010.

JUNIOR, Alípio Rodrigues Pines; SILVA, Tiago Aquino da Costa; LAZIER, Tatyanne Roiek et al. O Circo moderno: História, inovação e transição Social. FIEP BULLETIN, Vol. 83, Edição Especial, 2013. Disponível em:〈http://www.fiepbulletin.net/index.php/fiepbulletin/article/viewFile/2981/5815> acesso em 28 de maio de 2018.

KLAUSEN, Luciana dos Santos. Aprendizagem significativa: Um desafio. Educere, 2015. Disponível em<http://educere.bruc.com.br/arquivo/pdf2017/25702_12706.pdf> Acesso em 08 de agosto de 2018.

LIBÂNEO, JOSÉ CARLOS. Didática. São Paulo: Cortez, 1994.

LUCKESI, Cipriano Carlos. Avaliação da aprendizagem escola: estudos e proposições. $22^{a}$ ed. São Paulo: Cortez, 2011.

MARCONI, Marina de Andrade; LAKATOS, Eva Maria. Técnicas de Pesquisa: planejamento e execução de pesquisas, amostragens e técnicas de pesquisa, elaboração, análise e interpretação de dados. $7^{\mathrm{a}}$ ed. São Paulo: Atlas, 2008.

PELIZZARI, Adriana; KRIEGL, Maria de Lurdes et al. Teoria da aprendizagem significativa segundo Ausubel. Rev. PEC, Curitiba, v.2, n.1, p.37-42, jul. 2001-jul. 2002. Disponível em: $<$ http://files.gpecea-usp.webnode.com.br/200000393-74efd75e9b/MEQII-2013\%20TEXTOS\%20COMPLEMENTARES-\%20AULA\%205.pdf> Acesso 08 de Setembro de 2018 .

SAVIANI, Dermeval. Escola e democracia. São Paulo: Cortez/Ed.Assoc., 1980.

SEVERINO, Antonio Joaquim. Diretrizes para leitura, análise e interpretação. In: Metodologia do trabalho científico. 23 ed. São Paulo: Cortez, 2007, p. 49-65.

SILVA, Ermínia; ABREU, Luís Alberto de. Respeitável público...O circo em cena. $1^{\text {a }}$ ed. Rio de Janeiro. FUNARTE, 2009. 
SILVA, Georgia Valéria Oliveira da Mota; GUEDES, Juliana Vaz; RODRIGUES, Patrícia Tomaz Mattão. As dificuldades enfrentadas pela criança itinerante circense no processo de alfabetização. Simpósio de TCC e Seminário de IC, 2016

$12^{\circ}<$ Disponivel:http://nippromove.hospedagemdesites.ws/anais_simposio/arquivos_up/docum entos/artigos/ff89cace200dbde3a6bbc5fd16eedb6d.pdf> Acesso em 25 de agosto de 2018.

VERDUM, Priscila. Prática Pedagógica: O que é? O que envolve. Revista Educação por Escrito - PUCRS, v.4, n.1, jul. 2013 Disponível em

<http://revistaseletronicas.pucrs.br/ojs/index.php/porescrito/article/viewFile/14376/9703> Acesso em 12 de outubro de 2018.

ZABALA, Antonio. A Prática Educativa: Como Ensinar. Rio Grande do Sul. Artmed, 1998.

Submetido: $21 / 05 / 2020$

Aprovado: 23/08/2020 